\title{
Safety and Efficacy of Golimumab Administered Intravenously in Adults with Ankylosing Spondylitis: Results through Week 28 of the GO-ALIVE Study
}

\author{
Atul Deodhar, John D. Reveille, Diane D. Harrison, Lilianne Kim, Kim Hung Lo, \\ Jocelyn H. Leu, and Elizabeth C. Hsia
}

\begin{abstract}
Objective. To evaluate the safety and efficacy of intravenous golimumab (GOL) in patients with active ankylosing spondylitis (AS).

Methods. In a phase III, randomized, double-blind, placebo (PBO)-controlled trial, 208 patients were randomized (1:1) to intravenous (IV) infusions of GOL $2 \mathrm{mg} / \mathrm{kg}(\mathrm{n}=105)$ at weeks $0,4,12$, and every 8 weeks, or PBO $(n=103)$ at weeks 0,4 , and 12 , with crossover to GOL at Week 16 . The primary endpoint was $\geq 20 \%$ improvement from baseline in the Assessment of Spondyloarthritis International Society Criteria (ASAS20) at Week 16. Secondary endpoints included ASAS40, $\geq 50 \%$ improvement in the Bath Ankylosing Spondylitis Disease Activity Index (BASDAI50), and change in the Bath Ankylosing Spondylitis Functional Index (BASFI) at Week 16. Safety was monitored through Week 28.

Results. Significantly greater proportions of GOL-treated patients had ASAS20 response at Week 2 $(37.1 \%$ vs $19.4 \%$; $\mathrm{p}=0.005)$ and at Week $16(73.3 \%$ vs $26.2 \%$; $<<0.001)$. At Week $16,41.0 \%$ of those receiving GOL achieved BASDAI50 compared with $14.6 \%$ of those taking PBO ( $<<0.001)$, and the GOL group had greater mean improvement in BASFI $(-2.4$ vs $-0.5 ; \mathrm{p}<0.001)$. Through Week $16,23.3 \%$ of patients in the PBO group and $32.4 \%$ of patients in the GOL group had $\geq 1$ adverse event (AE); infections being the commonest type of AE. Through Week 28, two GOL-treated patients had a serious AE.

Conclusion. GOL $2 \mathrm{mg} / \mathrm{kg}$ administered IV at weeks 0,4 , and every 8 weeks significantly reduced the signs and symptoms of AS in adults. AE were consistent with other antitumor necrosis factor therapies, with no new safety signals (Clinicaltrials.gov: NCT02186873). (First Release December 15 2017; J Rheumatol 2018;45:341-8; doi:10.3899/jrheum.170487)
\end{abstract}

Key Indexing Terms:

GOLIMUMAB

INTRAVENOUS

\section{ANK YLOSING SPONDYLITIS ANTITUMOR NECROSIS FACTOR}

The American College of Rheumatology, the Spondylitis Association of America, and the Spondyloarthritis Research and Treatment Network (SPARTAN) treatment recommen-

From the Oregon Health \& Science University, Portland, Oregon; University of Texas McGovern Medical School, Houston, Texas; Janssen Research \& Development LLC, Spring House, Pennsylvania; University of Pennsylvania, Philadelphia, Pennsylvania, USA.

Study funded by Janssen Research \& Development LLC. AD has received consulting fees and research grants from Janssen. JDR has received consulting fees from Janssen. DDH, LK, KHL, JHL, and ECH are employees of Janssen and own stock in Johnson \& Johnson, of which Janssen Research \& Development LLC is a wholly owned subsidiary. A. Deodhar, MD, Oregon Health \& Science University; J.D. Reveille, MD, University of Texas McGovern Medical School; D.D. Harrison, MD, MPH, Janssen Research \& Development LLC; L. Kim, PhD, Janssen Research \& Development LLC; K.H. Lo, PhD, Janssen Research \& Development LLC; J.H. Leu, PharmD, PhD, Janssen Research \& Development LLC; E.C. Hsia, MD, MSCE, Janssen Research \& Development LLC, University of Pennsylvania.

Address correspondence to Dr. E.C. Hsia, Janssen Research and Development LLC, 1400 McKean Road, PO Box 776, Spring House, Pennsylvania 19477,USA.E-mail: ehsia@its.jnj.com

Full Release Article. For details see Reprints and Permissions at jrheum.org Accepted for publication August 11, 2017. dations suggest the use of antitumor necrosis factor (TNF) therapy for patients with active ankylosing spondylitis (AS) despite therapy with nonsteroidal antiinflammatory drugs (NSAID) ${ }^{1}$. Golimumab (GOL), a fully human monoclonal anti-TNF- $\alpha$ therapy, is currently approved for use as a subcutaneous (SC) injection for adult patients with rheumatoid arthritis (RA), psoriatic arthritis (PsA), and $\mathrm{AS}^{2}$, and also as an intravenous (IV) infusion for adults with $\mathrm{RA}^{3}$. In the phase III GO-FURTHER trial of patients with active RA despite methotrexate (MTX) therapy, IV GOL $2 \mathrm{mg} / \mathrm{kg}$ plus MTX demonstrated robust efficacy ${ }^{4}$ and a safety profile consistent with that of SC GOL in patients with $\mathrm{RA}^{5,6}, \mathrm{PsA}^{7}$, and $\mathrm{AS}^{8}$.

Given the various biologic treatment options available for $\mathrm{AS}^{1}$, patient preferences for some factors, such as route of administration and treatment setting, should be considered. Some patients are unable or unwilling to self-administer SC biologics at home and may prefer IV biologics. In a previous study, patients with RA receiving IV therapy generally preferred to receive their medication in a medical facility ${ }^{9}$, and in 1 study, patients cited "safety of the hospital administration" and "reassuring effect of the doctor's presence" as

Personal non-commercial use only. The Journal of Rheumatology Copyright $\subset$ C 2018. All rights reserved. 
reasons for preferring to receive their medication in a healthcare facility ${ }^{10}$. Some patients also prefer the less frequent dosing interval for IV therapies compared with SC therapies ${ }^{10}$. The approved dosing frequency for IV GOL in patients with RA is every 8 weeks after an induction regimen of 2 doses 4 weeks apart ${ }^{3}$ compared with monthly injections for $\mathrm{SC} \mathrm{GOL}^{2}$ and more frequent administrations (weekly or biweekly) for other SC anti-TNF therapies ${ }^{11,12}$. In the GO-ALIVE study, the safety and efficacy of IV GOL were evaluated in patients with AS, and results through Week 28 are reported herein.

\section{MATERIALS AND METHODS}

Patients. Those eligible were adults (aged $\geq 18$ yrs) with a diagnosis of AS (defined by the modified New York criteria ${ }^{13}$ ) for at least 3 months, having symptoms of active disease [Bath Ankylosing Spondylitis Disease Activity Index $(\mathrm{BASDAI})^{14} \geq 4$, a visual analog scale $(0-10 \mathrm{~cm})$ score for total back pain of $\geq 4$ ] at screening and at baseline, a high-sensitivity C-reactive protein level of $\geq 0.3 \mathrm{mg} / \mathrm{dl}$, and either an inadequate response or intolerance to NSAID. Patients with complete ankylosis of the spine were eligible, but were limited to $10 \%$ of the study population. Concomitant use of MTX ( $\leq 25 \mathrm{mg} /$ week), sulfasalazine (SSZ), hydroxychloroquine (HCQ), NSAID, other analgesics, and low-dose oral corticosteroids (dose equivalent to $\leq 10$ $\mathrm{mg}$ prednisone/day) was permitted at stable doses; patients were excluded if they had received systemic disease-modifying antirheumatic drugs other than MTX, SSZ, or HCQ within 4 weeks of the first study agent administration. A maximum of $20 \%$ of the study population could have received prior treatment with 1 anti-TNF other than GOL. These patients could not have experienced primary failure (defined as lack of response or discontinuation due to lack of efficacy within the first 16 weeks of treatment) to the anti-TNF therapy and could not have received the anti-TNF therapy within 3 months before the first study agent administration (except etanercept within 6 weeks). Previous treatment with other biologics, tofacitinib, or other Janus kinase inhibitors was not permitted.

Patients were screened for tuberculosis (TB) within 6 weeks before the first administration of study agent. Patients with evidence of active TB were excluded. Patients with latent TB were eligible if they were currently receiving treatment for latent $\mathrm{TB}$.

Study design. GO-ALIVE was a phase III, double-blind, placebo (PBO)-controlled trial. Eligible patients were randomly assigned (1:1) using an interactive Web-response system to receive IV infusions of PBO at weeks 0,4 , and 12 or GOL $2 \mathrm{mg} / \mathrm{kg}$ at weeks $0,4,12$, and every 8 weeks thereafter. Patients in the PBO group crossed over to receive GOL $2 \mathrm{mg} / \mathrm{kg}$ at weeks 16 and 20 and every 8 weeks thereafter. Patients randomized to the GOL group received a PBO infusion at Week 16 to maintain the blind. Randomization was stratified by geographic region and prior anti-TNF therapy (yes/no).

This trial was registered with clinicaltrials.gov (NCT02186873) and was conducted in accordance with the principles of the Declaration of Helsinki and Good Clinical Practices. All patients were required to give written informed consent before any study-related procedures were performed. The protocol was approved by Schulman Associates IRB for 10 sites in Canada (approval number: 201404734) and the United States (approval number: 201404241); the remaining 36 sites received approval from their local ethics committees.

Assessments. The primary endpoint was the proportion of patients who achieved an improvement of $\geq 20 \%$ in the Assessment of Spondyloarthritis International Society criteria (ASAS20 response) ${ }^{15}$ at Week 16 . Other efficacy endpoints included ASAS40 response, ASAS partial remission ${ }^{15}$, ASAS 5/6 response ${ }^{16}$, Ankylosing Spondylitis Disease Activity Score (ASDAS) inactive disease $(<1.3), \geq 50 \%$ improvement in BASDAI (BASDAI50 response), and changes in the Bath Ankylosing Spondylitis
Metrology Index (BASMI) ${ }^{17}$. Enthesitis was assessed using the University of California San Francisco enthesitis index ${ }^{18}$. Improvements in physical function were evaluated using the Bath Ankylosing Spondylitis Functional Index (BASFI) ${ }^{19}$. Health-related quality of life (HRQOL) was evaluated using the physical and mental component summary (PCS/MCS) scores of the Medical Outcomes Study Short Form-36 questionnaire (SF-36) and the Ankylosing Spondylitis Quality of Life (ASQoL) questionnaire ${ }^{20}$

Patients were monitored throughout the study for adverse events (AE), including hematology and chemistry assessments. Serum samples for the determination of GOL concentrations were collected through Week 20. These samples were also used for evaluation of the presence of antibodies to GOL using a recently developed, highly sensitive, drug-tolerant, enzyme immunoassay method in patients who received $\geq 1$ administration of GOL and had $\geq 1$ postadministration sample available.

Statistical analysis. The primary endpoint was the proportion of patients achieving an ASAS20 response at Week 16. Major secondary endpoints were ASAS40 response, BASDAI50 response, and change from baseline in BASFI, all at Week 16. For composite endpoints, missing components were imputed using last observation carried forward methodology if only some but not all components were missing; if all components were missing, those patients were classified as nonresponders for dichotomous endpoints. Patients who initiated prohibited therapies increased the dose of SSZ, MTX, HCQ, or oral corticosteroids above baseline level, or discontinued study agent owing to lack of efficacy prior to Week 16 were to be classified as nonresponders; no patient met these criteria. A Cochran-Mantel-Haenszel $(\mathrm{CMH})$ test was used to test differences between treatment groups for dichotomous endpoints. Mixed-effect model for repeated measures methodology based on observed data was used to analyze the controlled continuous endpoints. All statistical tests were performed at a 2-sided $\alpha=0.05$ level. To control for multiplicity, major secondary endpoints were tested sequentially (according to the order listed above) only when the primary endpoint achieved statistical significance. In addition, 5 other controlled secondary endpoints were also tested sequentially in the following order: change from baseline in SF-36 PCS, change from baseline in SF-36 MCS, proportion of patients achieving ASAS partial remission, change from baseline in ASQoL, and change from baseline in BASMI (linear) ${ }^{21}$, all at Week 16. For other efficacy endpoints, nominal $\mathrm{p}$ values were provided.

It was estimated that 100 patients in each treatment group would provide about $93 \%$ power to detect the treatment difference between $\mathrm{PBO}$ and GOL for the primary endpoint assuming a PBO response rate of $25 \%$ and a GOL response rate of $40 \%$ (patients with prior anti-TNF therapy) and $50 \%$ (patients with no prior anti-TNF therapy), using a CMH test at $\alpha=0.05$ (2-sided)

\section{RESULTS}

Patient disposition and baseline characteristics. Data for this report were collected from September 2014 to March 2016. There were 312 patients screened from 46 sites; of these, 208 from 40 sites in 8 countries (Canada, Germany, Republic of Korea, Mexico, Poland, Russia, Ukraine, and the United States) were randomized to PBO $(n=103)$ or GOL $(n=105)$ and treated. Through Week 16, 4 patients (all in the PBO group) discontinued treatment: 3 withdrew consent and 1 was lost to followup (Figure 1). After Week 16 and through Week 28, 1 additional patient (GOL group) discontinued treatment; this patient discontinued study agent because of $\mathrm{AE}$ of increased alanine aminotransferase (ALT) and increased aspartate aminotransferase (AST), neither considered by the investigator to be related to study medication.

Overall, $78 \%$ of patients were male, and the mean age was 39 years. Mean time since AS diagnosis was 5.5 years; $89.9 \%$

Personal non-commercial use only. The Journal of Rheumatology Copyright $\odot$ (2018. All rights reserved 


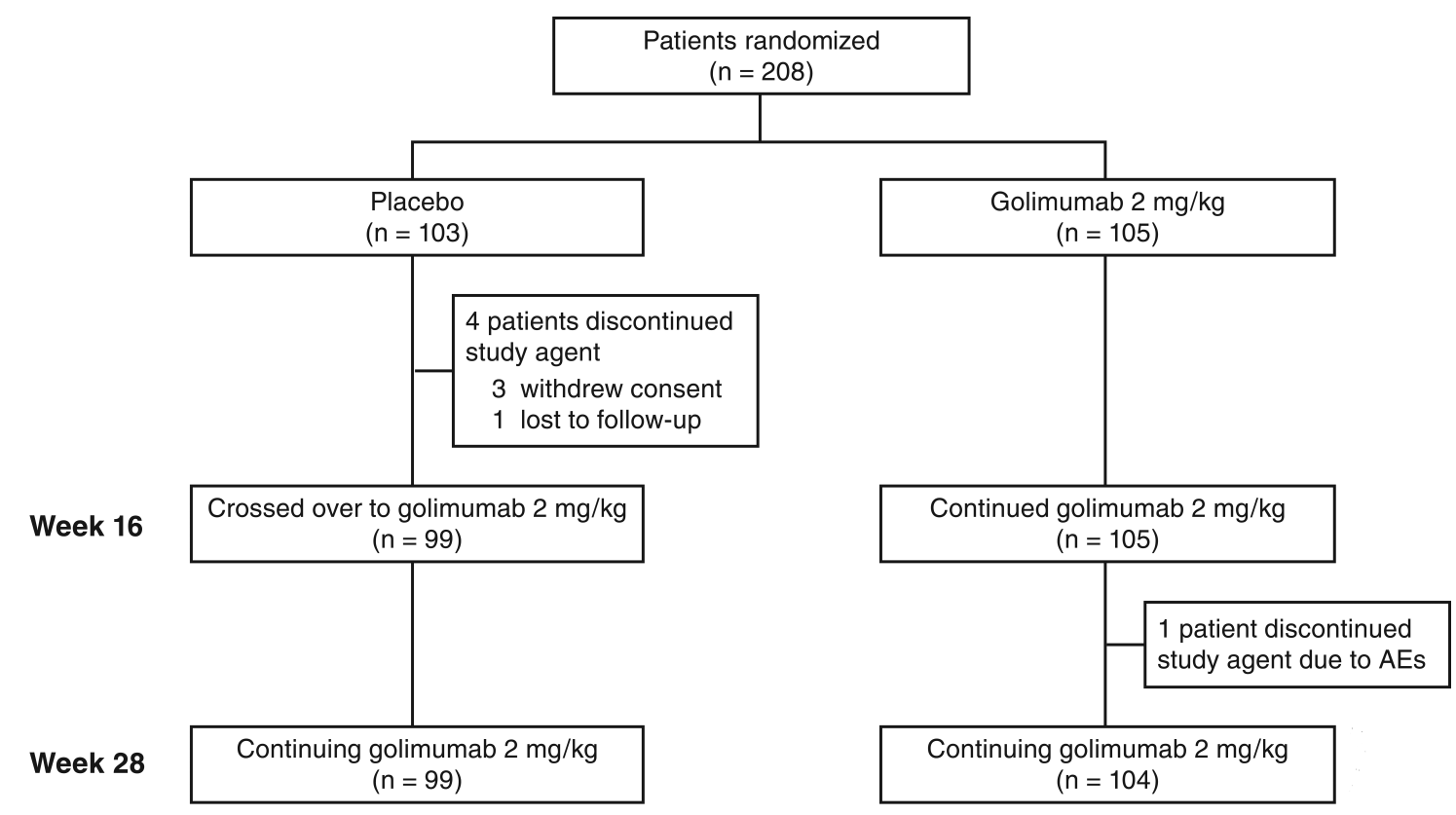

Figure 1. Patient disposition through Week 28. AE: adverse event.

were HLA-B27-positive, and 12 patients (5.8\%) had complete ankylosis of the spine (Table 1). Baseline demographic and disease characteristics were generally comparable between the treatment groups. Thirty patients $(\mathrm{PBO}, \mathrm{n}=14 ; \mathrm{GOL}, \mathrm{n}=16$ ) had received prior therapy with 1 anti-TNF agent.

Clinical efficacy and HRQOL. The primary endpoint was achieved by $73.3 \%$ of patients in the GOL group who demonstrated an ASAS20 response compared with $26.2 \%$ in the PBO group at Week 16 ( $p<0.001$; Table 2$)$, with a significantly greater proportion of GOL-treated patients having an ASAS20 response at Week 2 compared with PBO (37.1\% vs $19.4 \% ; \mathrm{p}=0.005)$. The robustness of the primary endpoint was supported by 8 sensitivity analyses using various data handling and treatment failure rules (data not shown). Greater proportions of patients in the GOL group had $\geq 20 \%$ improvement in each of the 4 individual ASAS components (patient's global assessment of disease activity, patient's global assessment of total back pain, BASFI, and inflammation) at Week 16 compared with PBO (Table 2). In addition, significantly greater proportions of patients in the GOL group achieved ASAS40 response, ASAS partial remission, and ASAS 5/6 response at Week 16 compared with PBO (Table 2). After Week 16, the proportions of patients achieving an ASAS20 and ASAS40 response were maintained through Week 28 for patients in the GOL group; among patients who initially received $\mathrm{PBO}$ and crossed over to GOL at Week 16, improvements were observed at Week 20 and maintained through Week 28 (Figure 2).

Other measures of disease activity were also evaluated. The proportion of patients with a BASDAI50 response was also significantly greater in the GOL group compared with
PBO at Week 16 (Table 2). Additionally, the mean change in ASDAS score from baseline to Week 16 was -0.4 in the PBO group and -2.0 in the GOL group $(\mathrm{p}<0.001)$. Response rates for ASDAS inactive disease were also significantly greater in the GOL group compared with PBO at Week $2(7.6 \%$ vs $0 \% ; p=0.004)$ and Week $16(20.0 \%$ vs $2.9 \% ; p<0.001)$. For patients randomized to $\mathrm{PBO}$, the proportions of patients achieving BASDAI50 response and ASDAS inactive disease increased at Week 20, following crossover to GOL, and were maintained through Week 28 (Figure 2).

The mean improvement in physical function (BASFI) at Week 16 was also significantly greater in the GOL group compared with PBO (-2.4 vs $-0.5 ; \mathrm{p}<0.001)$. The mean improvement from baseline in BASMI score was also greater in the GOL group compared with PBO at Week 16 ( -0.4 vs $-0.1 ; \mathrm{p}=0.001)$. At Week 28 , the mean change from baseline in BASMI score for patients in the PBO group $(-0.3)$, who began receiving GOL at Week 16 , improved nearly to that for patients in the GOL group (-0.4). Among patients with enthesitis at baseline, those in the GOL group had greater mean changes from baseline in enthesitis score when compared with the PBO group at weeks $2(-2.3$ vs -0.7$)$ and $16(-3.5$ vs $-1.2 ; \mathrm{p}<0.001$ for both).

Patients in the GOL group also had significantly greater improvements in HRQOL at Week 16 compared with the PBO group, as demonstrated by mean improvements from baseline in SF-36 PCS/MCS and ASQoL scores (Table 3).

Among patients with complete ankylosis of the spine at study enrollment, 0 of 7 in the PBO group and 3 of $5(60.0 \%)$ in the GOL group achieved an ASAS20 response at Week 16 $(\mathrm{p}=0.018)$. Additionally, in posthoc analyses in this

Personal non-commercial use only. The Journal of Rheumatology Copyright (C) 2018. All rights reserved. 
Table 1. Baseline demographic and disease characteristics. Data are presented as mean \pm SD unless otherwise noted.

\begin{tabular}{|c|c|c|}
\hline Characteristics & Placebo & $\begin{array}{l}\text { Golimumab, } \\
2 \mathrm{mg} / \mathrm{kg}\end{array}$ \\
\hline Patients randomized, $\mathrm{n}$ & 103 & 105 \\
\hline Age, yrs & $39.2 \pm 10.8$ & $38.4 \pm 10.1$ \\
\hline Male, n (\%) & $77(74.8)$ & $86(81.9)$ \\
\hline \multicolumn{3}{|l|}{ Time since inflammatory back pain } \\
\hline Time since diagnosis of AS, yrs & $5.5 \pm 5.9$ & $5.6 \pm 6.6$ \\
\hline $\begin{array}{l}\text { Patients with complete ankylosis } \\
\text { the spine, } \mathrm{n}(\%)\end{array}$ & $7(6.8)$ & $5(4.8)$ \\
\hline \multicolumn{3}{|l|}{ ASAS components } \\
\hline \multicolumn{3}{|c|}{ Patient's global assessment of disease } \\
\hline \multicolumn{3}{|c|}{ Patient's assessment of total back pain, } \\
\hline VAS 0-10 cm & $7.3 \pm 1.5$ & $7.2 \pm 1.3$ \\
\hline BASFI & $6.1 \pm 2.0$ & $6.3 \pm 1.9$ \\
\hline Inflammation & $7.4 \pm 1.6$ & $7.3 \pm 1.5$ \\
\hline BASDAI & $7.1 \pm 1.2$ & $7.0 \pm 1.2$ \\
\hline ASDAS & $4.1 \pm 0.8$ & $4.2 \pm 0.7$ \\
\hline BASMI & $5.0 \pm 0.8$ & $5.0 \pm 0.9$ \\
\hline $\mathrm{CRP}, \mathrm{mg} / \mathrm{l}$ & $19.3 \pm 16.7$ & $20.0 \pm 18.2$ \\
\hline \multicolumn{3}{|l|}{ Prior anti-TNF therapy, $n$} \\
\hline Adalimumab & 0 & 1 \\
\hline Certolizumab & 3 & 8 \\
\hline Etanercept & 2 & 0 \\
\hline Infliximab & 9 & 7 \\
\hline SF-36 PCS score & $32.1 \pm 5.9$ & $32.4 \pm 5.6$ \\
\hline SF-36 MCS score & $41.9 \pm 10.2$ & $40.0 \pm 10.4$ \\
\hline ASQoL & $12.4 \pm 4.1$ & $12.8 \pm 4.0$ \\
\hline \multicolumn{3}{|l|}{ Concomitant medication use } \\
\hline \multicolumn{3}{|l|}{ Oral corticosteroids } \\
\hline Patients, n (\%) & $23(22.3)$ & $32(30.5)$ \\
\hline Dose, $\mathrm{mg} /$ day $^{\mathrm{a}}$ & $6.1 \pm 2.5$ & $7.8 \pm 2.7$ \\
\hline \multicolumn{3}{|l|}{ MTX } \\
\hline Patients, n (\%) & $21(20.4)$ & $15(14.3)$ \\
\hline Dose, $\mathrm{mg} /$ week & $13.7 \pm 5.0$ & $16.7 \pm 4.9$ \\
\hline NSAID, n (\%) & $90(87.4)$ & $94(89.5)$ \\
\hline Sulfasalazine, n (\%) & $39(37.9)$ & $41(39.0)$ \\
\hline
\end{tabular}

aDose equivalent to prednisone/day. AS: ankylosing spondylitis; ASAS: ASsessment in Ankylosing Spondylitis International Working Group criteria; ASDAS: Ankylosing Spondylitis Disease Activity Score; ASQoL: Ankylosing Spondylitis Quality of Life; BASDAI: Bath Ankylosing Spondylitis Disease Activity Index; BASFI: Bath Ankylosing Spondylitis Functional Index; BASMI: Bath Ankylosing Spondylitis Metrology Index; CRP: C-reactive protein; MTX: methotrexate; NSAID: nonsteroidal antiinflammatory drugs; SF-36 PCS/MCS: physical and mental component summary of the Medical Outcomes Study Short Form-36 questionnaire; TNF: tumor necrosis factor; VAS: visual analog scale.

subgroup, the response rates for ASAS40 and BASDAI50 and mean changes from baseline in BASFI and BASMI scores were numerically greater in the GOL group compared with PBO (Appendix 1).

Analysis of AE. Through Week 16, 23.3\% of patients in the $\mathrm{PBO}$ group and $32.4 \%$ of patients in the GOL group had 1 or more AE (Table 4). Infections were the most common type of $\mathrm{AE}$ (PBO, 7.8\%; GOL, 11.4\%); of these, nasopharyngitis
Table 2. Clinical efficacy at Week 16. Data presented as n (\%) unless otherwise noted.

\begin{tabular}{|c|c|c|}
\hline Characteristics & Placebo & $\begin{array}{l}\text { Golimumab, } \\
2 \mathrm{mg} / \mathrm{kg}\end{array}$ \\
\hline Patients randomized, $\mathrm{n}$ & 103 & 105 \\
\hline ASAS20 & $27(26.2)$ & $77(73.3)^{* *}$ \\
\hline ASAS40 & $9(8.7)$ & $50(47.6)^{* *}$ \\
\hline ASAS partial remission & $4(3.9)$ & $17(16.2)^{*}$ \\
\hline ASAS 5/6 response & $12(11.7)$ & $68(64.8) * *$ \\
\hline ASDAS inactive disease & $3(2.9)$ & $21(20.0)^{* *}$ \\
\hline BASDAI50 & $15(14.6)$ & $43(41.0)^{* *}$ \\
\hline \multicolumn{3}{|l|}{ Change from baseline in ASDAS, } \\
\hline \multicolumn{2}{|l|}{ Change from baseline in BASFI, } & $105(-2.4 \pm 2.1 * *)$ \\
\hline \multicolumn{2}{|c|}{ Change from baseline in BASMI (linear), } & $100(-0.4 \pm 0.6 * *)$ \\
\hline \multicolumn{3}{|c|}{ Patients with $\geq 20 \%$ improvement in ASAS components } \\
\hline $\begin{array}{l}\text { Patient's global assessment of } \\
\text { disease activity }\end{array}$ & $34(33.0)$ & $86(81.9)^{* *}$ \\
\hline Patient's assessment of total back pain & n $38(36.9)$ & $74(70.5)^{* *}$ \\
\hline BASFI & $33(32.0)$ & $75(71.4)^{* *}$ \\
\hline Inflammation & $37(35.9)$ & $83(79.0)^{* *}$ \\
\hline
\end{tabular}

$* \mathrm{p}<0.01 . * * \mathrm{p} \leq 0.001$. ASAS20/40: $\geq 20 \% / 40 \%$ improvement in ASsessment in Ankylosing Spondylitis (ASAS) International Working Group criteria; ASDAS: Ankylosing Spondylitis Disease Activity Score; BASDAI50: $\geq 50 \%$ improvement in Bath Ankylosing Spondylitis Disease Activity Index; BASFI: Bath Ankylosing Spondylitis Functional Index; BASMI: Bath Ankylosing Spondylitis Metrology Index.

and upper respiratory tract infection were the most frequent. Three patients, all in the GOL group (2.9\%), had an infusion reaction (fatigue, dizziness, rash); none was considered serious or severe. Two patients had a serious AE (SAE; pneumonia, $\mathrm{n}=1$; pancreatitis, $\mathrm{n}=1$ ); both occurred in the GOL group. Three patients, all in the PBO group, reported eye disorders through Week 16; 1 patient reported eye pain with no history of other eye symptoms, and 2 patients with a history of uveitis that was not ongoing at the start of the trial reported iritis $(\mathrm{n}=1)$ and uveitis $(\mathrm{n}=1)$ through Week 16.

Through Week 28, 34.8\% of all GOL-treated patients (i.e., all patients in the GOL group and all patients in the PBO group who received $\geq 1$ infusion of GOL) had $\geq 1 \mathrm{AE}$ (Table $4)$; infections were the most common type (17.2\%). No additional patients experienced an infusion reaction or an SAE between weeks 16 and 28. There were no reports of new or worsening inflammatory bowel disease and no reports of depression, demyelination, opportunistic infection, malignancy, or death through Week 28. There were no cases of anaphylaxis or serum sickness-like reactions.

Through Week 28, 22.1\% of all GOL-treated patients had an ALT value in the normal range at baseline and a postbaseline abnormal ALT value. Most of these patients had maximum ALT values of $<2 \times$ the upper limit of normal (ULN). One patient had an increase $\geq 3$ to $<5 \times$ ULN; none had an increase $\geq 5 \times$ ULN 
A

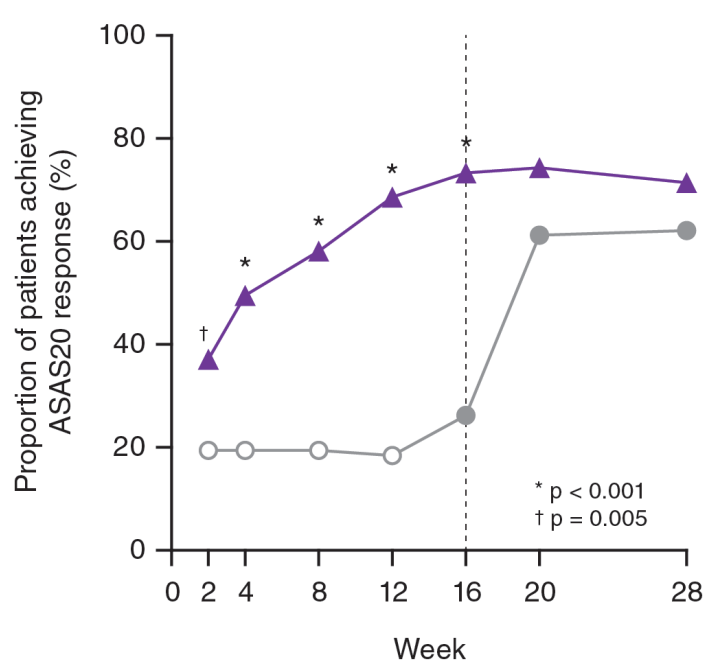

C

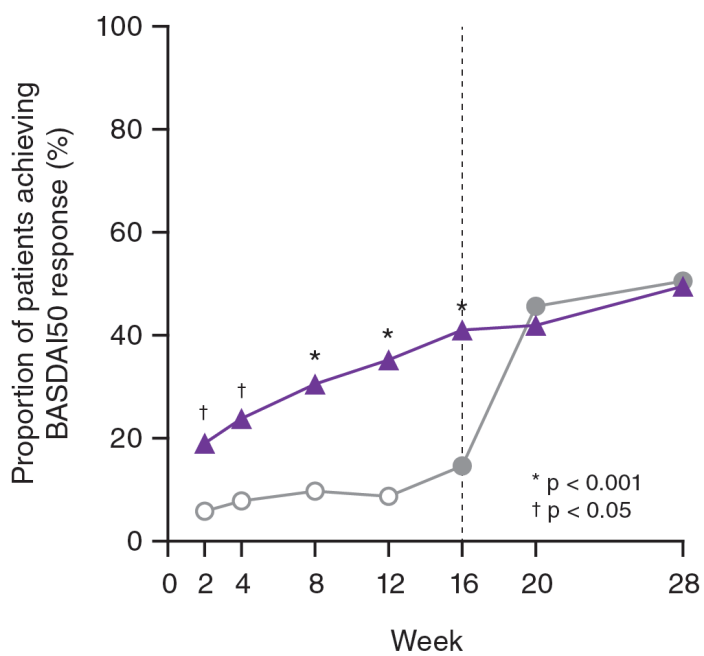

B

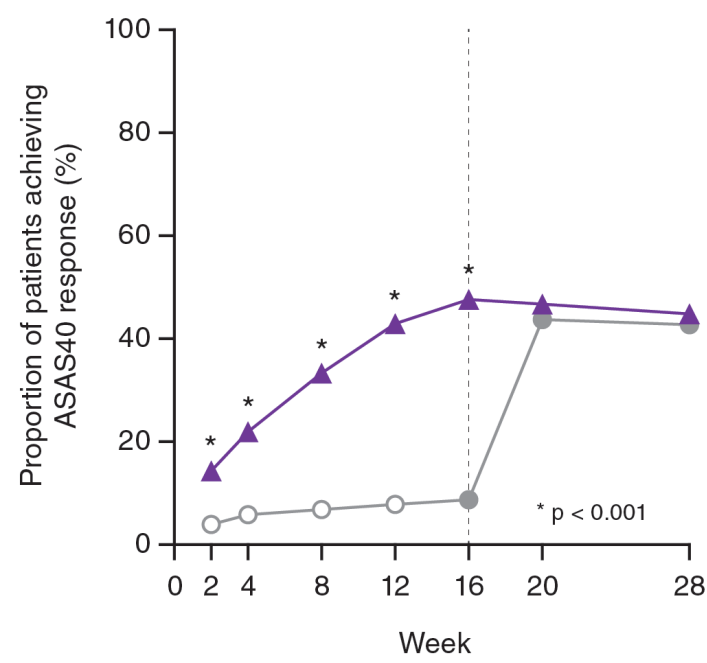

D

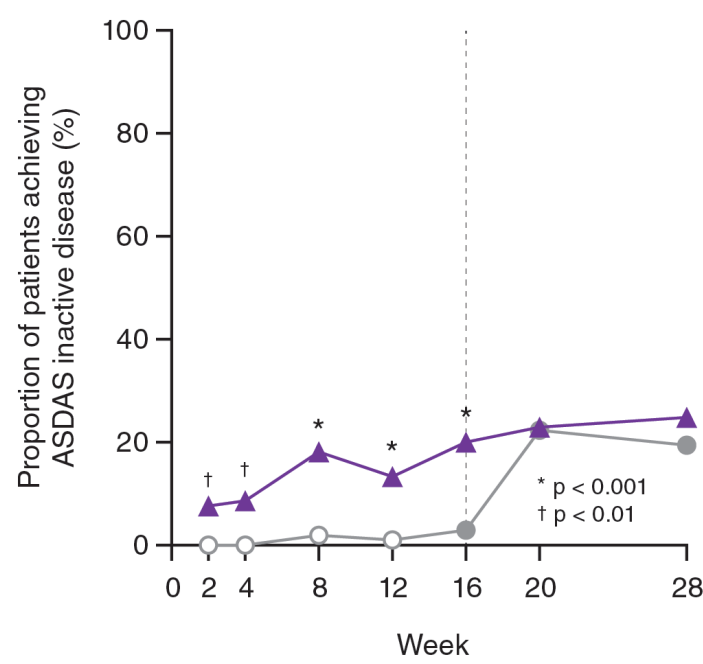

$\longrightarrow$ Golimumab $2 \mathrm{mg} / \mathrm{kg}(\mathrm{n}=105)$

Figure 2. Proportion of patients achieving an ASAS20 response (A), ASAS40 response (B), BASDAI50 response (C), or ASDAS inactive disease (D) through Week 28. Patients randomized to placebo crossed over to golimumab $2 \mathrm{mg} / \mathrm{kg}$ at Week 16 (dotted line). ASAS20/40: $\geq 20 \% / 40 \%$ improvement in ASsessment in Ankylosing Spondylitis International Working Group criteria; ASDAS: Ankylosing Spondylitis Disease Activity Score; BASDAI50: $\geq 50 \%$ improvement in Bath Ankylosing Spondylitis Disease Activity Index.

Among GOL-treated patients, $10.3 \%$ had an AST value in the normal range at baseline and a postbaseline abnormal AST value through Week 28 . All of these increases were $<2$ $\times$ ULN.

Twenty-one GOL-treated patients received prophylaxis for latent TB during the study; none developed active TB. One-third had an elevated ALT level through Week 28; all increases were $<3 \times$ ULN. Three patients had an elevated AST level through Week 28; all increases were $<2 \times$ ULN.

Pharmacokinetics and immunogenicity. After administration of IV GOL $2 \mathrm{mg} / \mathrm{kg}$ at weeks 0,4 , and every 8 weeks, median trough serum GOL concentration reached steady state by Week 12 and was maintained at Week $20(0.65 \mu \mathrm{g} / \mathrm{ml})$. Among GOL-treated patients, 20 (19.0\%) tested positive for antibodies to GOL through Week 20 using a highly sensitive, drug-tolerant immunoassay. Among the 20 antibody-positive patients, 6 were positive for neutralizing antibodies. Median trough GOL concentrations tended to be lower in patients who were positive for antibodies to GOL, and GOL concentrations tended to decrease as peak titers increased. At Week $20,13(65 \%)$ of the 20 antibody-positive patients had an ASAS20 response, and $6(30 \%)$ had an ASAS40 response;

Personal non-commercial use only. The Journal of Rheumatology Copyright @ 2018 . All rights reserved. 
Table 3. Health-related quality of life at Week 16. Data are $n($ mean \pm SD) unless otherwise indicated.

\begin{tabular}{|c|c|c|}
\hline Variables & Placebo & $\begin{array}{l}\text { Golimumab, } \\
2 \mathrm{mg} / \mathrm{kg}\end{array}$ \\
\hline Patients randomized, $\mathrm{n}$ & 103 & 105 \\
\hline $\begin{array}{l}\text { Change from baseline in } \\
\text { SF-36 PCS score }\end{array}$ & $98(2.9 \pm 6.2)$ & $104\left(8.5 \pm 7.5^{*}\right)$ \\
\hline $\begin{array}{l}\text { Change from baseline in } \\
\text { SF-36 MCS score } \\
\text { Change from baseline in ASQoL }\end{array}$ & $\begin{array}{l}98(0.8 \pm 10.0) \\
98(-1.8 \pm 4.6)\end{array}$ & $\begin{array}{c}104(6.5 \pm 9.1 *) \\
104\left(-5.4 \pm 5.0^{*}\right)\end{array}$ \\
\hline
\end{tabular}

*p $\leq$ 0.001. ASQoL: Ankylosing Spondylitis Qualify of Life; SF-36 PCS/MCS: physical and mental component summary of the Medical Outcomes Study Short Form-36 questionnaire.

among the 84 patients who tested negative for antibodies to GOL, $65(77 \%)$ had an ASAS20 response and $43(51 \%)$ had an ASAS40 response. None of the infusion reactions occurred in patients who tested positive for antibodies to GOL.

\section{DISCUSSION}

Through Week 28 of the GO-ALIVE study, the signs and symptoms of AS were significantly improved among patients treated with IV GOL $2 \mathrm{mg} / \mathrm{kg}$ compared with those receiving PBO. The primary endpoint was achieved, with $73 \%$ of patients in the GOL group achieving an ASAS20 response at Week 16 compared with $26 \%$ of patients in the PBO group, and separation between the GOL and the PBO group was observed as early as Week 2. Of note, among the small subgroup of patients who had complete ankylosis of the spine, 3 of the 5 GOL-treated patients achieved an ASAS20 response at Week 16 compared with no patient in the PBO group. Additional data are needed to assess the efficacy of IV GOL in patients with complete ankylosis.

All major secondary endpoints were met, which demonstrated that the response to IV GOL in this population was robust. Mean improvements in clinical efficacy measures and HRQOL were significantly greater in the GOL group compared with $\mathrm{PBO}$. The significantly greater improvements in the SF-36 MCS score with IV GOL compared with PBO are particularly notable in this patient population $8,22,23$.

Current treatment recommendations for adults with AS outline various therapy options with the overall treatment goals being to "reduce symptoms, maintain spinal flexibility and normal posture, reduce functional limitations, maintain work ability, and decrease disease complications" ${ }^{\text {. These }}$ recommendations support the use of anti-TNF therapy for patients with active AS despite receiving NSAID. The treatto-target concept is not as well developed for spondyloarthritides as with $\mathrm{RA}^{24}$; however, an international task force currently suggests that clinical remission/inactive disease of musculoskeletal symptoms should be a major treatment target ${ }^{25}$. Nearly $30 \%$ of patients randomized to GOL in GO-ALIVE achieved ASDAS inactive disease at Week 16.

GOL has demonstrated efficacy in patients with AS by both $\mathrm{SC}^{8}$ and IV routes of administration. Currently, GOL is the only anti-TNF therapy that can be administered as either an SC injection (monthly) or an IV infusion (over $30 \mathrm{~min}$ every 8 weeks). Patients often have preferences for mode and frequency of treatment administration for biologic therapies ${ }^{9,10}$. Patient involvement in determining treatment decisions has been shown to improve treatment satisfaction ${ }^{26}$ and also efficacy outcomes ${ }^{27}$. Thus, the international task force treatment recommendations support the consideration of patient preferences as part of the shared decision-making discussion with physicians ${ }^{25}$.

There was a higher incidence of AE with GOL than with PBO through Week 16, which is consistent with previous PBO-controlled trials of anti-TNF therapies in $\mathrm{AS}^{8,22,28}$. Infections were the most common type of AE; most were not classified by the investigators as serious or severe. Few infusion reactions were reported. Two SAE occurred; both in the GOL group (pneumonia and pancreatitis) and before Week 16, with no additional SAE between weeks 16 and 28. No cases of new or worsening inflammatory bowel disease

Table 4. Adverse events through Week 28. Data presented as n (\%) unless otherwise noted.

\begin{tabular}{lccc}
\hline \multirow{2}{*}{ Variables } & \multicolumn{2}{c}{ Weeks 0-16 } & Weeks 0-28 \\
& Placebo & GOL, 2 mg/kg & $\begin{array}{c}\text { Combined GOL, } \\
2 \mathrm{mg} / \mathrm{kg} *\end{array}$ \\
\hline Patients, $\mathrm{n}$ & & & 204 \\
Mean duration of followup, weeks & 103 & 105 & 20.2 \\
Patients who discontinued because of an AE & 16.0 & 16.1 & $1(0.5)$ \\
Patients with $\geq 1$ AE & 0 & 0 & $71(34.8)$ \\
Patients with $\geq 1$ infection & $24(23.3)$ & $34(32.4)$ & $35(17.2)$ \\
Patients with $\geq 1$ infusion reaction & $8(7.8)$ & $12(11.4)$ & $3(1.5)$ \\
Patients with $\geq 1$ SAE & 0 & $3(2.9)$ & $2(1.0)$ \\
Serious infections & 0 & $2(1.9)$ & $1(0.5)$ \\
Malignancies & 0 & $1(1.0)$ & 0 \\
Deaths & 0 & 0 & 0 \\
\hline
\end{tabular}

* The combined GOL group includes patients randomized to the placebo group who crossed over to GOL at Week 16 and patients randomized to the GOL group at baseline. GOL: golimumab; AE: adverse event; SAE: serious AE. 
occurred through Week 28, and there were no reports of depression, demyelination, opportunistic infection, malignancy, or death.

Twenty patients tested positive for antibodies to GOL using a highly sensitive, drug-tolerant assay, which was consistent with other rheumatologic indications tested with the drug-tolerant immunoassay. The higher incidence of antibodies to GOL in comparison with the previous assay ${ }^{3}$ was expected from using a more sensitive assay and was mostly due to low titer antibodies, which did not have an apparent effect on drug concentrations or efficacy. Higher titer antibodies, which were mostly neutralizing, appeared to be associated with lower GOL concentrations and diminished efficacy; however, there were too few patients with these high titers to draw any firm conclusions. Overall, development of antibodies to GOL did not preclude clinical response and there did not appear to be an effect of antibodies to GOL on infusion reactions because no infusion reaction occurred in patients who tested positive for antibodies to GOL.

The results through Week 28 of the GO-ALIVE study demonstrated significantly greater clinical response and improvements in HRQOL with GOL compared with PBO in patients with AS. The incidence and type of AE that occurred through Week 28 were consistent with the established safety profile of anti-TNF therapies in patients with AS, and no new safety signals were identified. The safety and efficacy of IV GOL $2 \mathrm{mg} / \mathrm{kg}$ in this patient population will be reported through 1 year in a subsequent publication.

\section{ACKNOWLEDGMENT}

The authors thank Stephen Xu, MS, of Janssen Research \& Development LLC for statistical support, and Rebecca E. Clemente, PhD, of Janssen Scientific Affairs LLC for writing support. These investigators randomized patients in the GO-ALIVE trial: Vikas Pandith, Proton Rahman (Canada); Gunther Neeck, Siegfried Wassenberg, Martin Welcker, Juegen Wollenhaupt (Germany); Sung-Jae Choi, Seung-Jae Hong, Tae-Hwan Kim, Sang Hoon Lee, Shink-Seok Lee (Republic of Korea); Cesar Francisco Pacheco Tena (Mexico); Anna Dudek, Maria Glowacka-Kulesz, Pawel Hrycaj, Slawomir Jeka, Marek Krogulec, Malgorzata Miakisz, Anna Zubrzycka-Sienkiewicz (Poland); Valerii Marchenko, Galina Matsievskaya, Anna Novikova, Dmitry Platonov, Olga Reshetko, Evgeniya Shmidt, Liudmilla Zharkova (Russia); Olena Garmish, Oleg Iaremenko, Olena Levchenko, Olena Lysunets, Dmitro Rekalov, Valentyna Romaniuk, Sergii Shevchuk, Mykola Stanislavchuk (Ukraine); Tina Bunch, Paul Caldron, Akgun Ince, Ramina Jajoo, Frederick Murphy, John D. Reveille (USA).

\section{REFERENCES}

1. Ward MM, Deodhar A, Akl EA, Lui A, Ermann J, Gensler LS, et al. American College of Rheumatology/Spondylitis Association of America/Spondyloarthritis Research and Treatment Network 2015 recommendations for the treatment of ankylosing spondylitis and nonradiographic axial spondyloarthritis. Arthritis Rheumatol 2016;68:282-98.

2. Simponi: Package insert. Horsham, Pennsylvania: Janssen Biotech Inc.; 2016

3. Simponi ARIA: Package insert. Horsham, Pennsylvania: Janssen Biotech Inc.; 2016.

4. Weinblatt ME, Bingham CO 3rd, Mendelsohn AM, Kim L, Mack $\mathrm{M}, \mathrm{Lu} \mathrm{J}$, et al. Intravenous golimumab is effective in patients with active rheumatoid arthritis despite methotrexate therapy with responses as early as week 2 : results of the phase 3 , randomised, multicentre, double-blind, placebo-controlled GO-FURTHER trial. Ann Rheum Dis 2013;72:381-9.

5. Emery P, Fleischmann RM, Moreland LW, Hsia EC, Strusberg I, Durez P, et al. Golimumab, a human anti-tumor necrosis factor alpha monoclonal antibody, injected subcutaneously every four weeks in methotrexate-naive patients with active rheumatoid arthritis: twenty-four-week results of a phase III, multicenter, randomized, double-blind, placebo-controlled study of golimumab before methotrexate as first-line therapy for early-onset rheumatoid arthritis. Arthritis Rheum 2009;60:2272-83.

6. Keystone EC, Genovese MC, Klareskog L, Hsia EC, Hall ST, Miranda PC, et al. Golimumab, a human antibody to tumour necrosis factor [alpha] given by monthly subcutaneous injections, in active rheumatoid arthritis despite methotrexate therapy: the GO-FORWARD Study. Ann Rheum Dis 2009;68:789-96.

7. Kavanaugh A, McInnes I, Mease P, Krueger GG, Gladman D, Gomez-Reino J, et al. Golimumab, a new human tumor necrosis factor alpha antibody, administered every four weeks as a subcutaneous injection in psoriatic arthritis: Twenty-four-week efficacy and safety results of a randomized, placebo-controlled study. Arthritis Rheum 2009;60:976-86.

8. Inman RD, Davis JC Jr., van der Heijde D, Diekman L, Sieper J, Kim SI, et al. Efficacy and safety of golimumab in patients with ankylosing spondylitis: results of a randomized, double-blind, placebo-controlled, phase III trial. Arthritis Rheum 2008; 58:3402-12.

9. Sylwestrzak G, Liu J, Stephenson JJ, Ruggieri AP, DeVries A. Considering patient preferences when selecting anti-tumor necrosis factor therapeutic options. Am Health Drug Benefits 2014;7:71-81.

10. Scarpato S, Antivalle M, Favalli EG, Nacci F, Frigelli S, Bartoli F, et al. Patient preferences in the choice of anti-TNF therapies in rheumatoid arthritis. Results from a questionnaire survey (RIVIERA study). Rheumatology 2010;49:289-94.

11. Humira: Package insert. Abbott Park, Illinois: AbbVie Inc.; 2016.

12. Enbrel: Package insert. Thousand Oaks, California: Amgen; 2016

13. van der Linden S, Valkenburg HA, Cats A. Evaluation of diagnostic criteria for ankylosing spondylitis. A proposal for modification of the New York criteria. Arthritis Rheum 1984;27:361-8.

14. Garrett S, Jenkinson T, Kennedy LG, Whitelock H, Gaisford P, Calin A. A new approach to defining disease status in ankylosing spondylitis: the Bath Ankylosing Spondylitis Disease Activity Index. J Rheumatol 1994;21:2286-91.

15. Anderson JJ, Baron G, van der Heijde D, Felson DT, Dougados M. Ankylosing Spondylitis Assessment Group preliminary definition of short-term improvement in ankylosing spondylitis. Arthritis Rheum 2001;44:1876-86.

16. Sieper J, Rudwaleit M, Baraliakos X, Brandt J, Braun J, Burgos-Vargas R, et al. The Assessment of SpondyloArthritis international Society (ASAS) handbook: a guide to assess spondyloarthritis. Ann Rheum Dis 2009;68 Suppl 2:ii1-44.

17. Jenkinson TR, Mallorie PA, Whitelock HC, Kennedy LG, Garrett SL, Calin A. Defining spinal mobility in ankylosing spondylitis (AS). The Bath AS Metrology Index. J Rheumatol 1994;21:1694-8.

18. Gorman JD, Sack KE, Davis JC Jr. Treatment of ankylosing spondylitis by inhibition of tumor necrosis factor alpha. N Engl J Med 2002;346:1349-56.

19. Calin A, Garrett S, Whitelock H, Kennedy LG, O'Hea J, Mallorie P, et al. A new approach to defining functional ability in ankylosing spondylitis: the development of the Bath Ankylosing Spondylitis Functional Index. J Rheumatol 1994;21:2281-5.

20. Doward LC, Spoorenberg A, Cook SA, Whalley D, Helliwell PS, Kay LJ, et al. Development of the ASQoL: a quality of life instrument specific to ankylosing spondylitis. Ann Rheum Dis 2003;62:20-6.

Personal non-commercial use only. The Journal of Rheumatology Copyright @ 2018. All rights reserved. 
21. van der Heijde D, Landewe R, Feldtkeller E. Proposal of a linear definition of the Bath Ankylosing Spondylitis Metrology Index (BASMI) and comparison with the 2-step and 10-step definitions. Ann Rheum Dis 2008;67:489-93.

22. Brandt J, Khariouzov A, Listing J, Haibel H, Sorensen H, Grassnickel L, et al. Six-month results of a double-blind, placebo-controlled trial of etanercept treatment in patients with active ankylosing spondylitis. Arthritis Rheum 2003;48:1667-75

23. Davis JC Jr., Revicki D, van der Heijde DM, Rentz AM, Wong RL, Kupper $\mathrm{H}$, et al. Health-related quality of life outcomes in patients with active ankylosing spondylitis treated with adalimumab: results from a randomized controlled study. Arthritis Rheum 2007; 57:1050-7.

24. Smolen JS, Breedveld FC, Burmester GR, Bykerk V, Dougados M, Emery P, et al. Treating rheumatoid arthritis to target: 2014 update of the recommendations of an international task force. Ann Rheum Dis 2016;75:3-15.

25. Smolen JS, Braun J, Dougados M, Emery P, Fitzgerald O, Helliwell $\mathrm{P}$, et al. Treating spondyloarthritis, including ankylosing spondylitis and psoriatic arthritis, to target: recommendations of an international task force. Ann Rheum Dis 2014;73:6-16.

26. Umar N, Schaarschmidt M, Schmieder A, Peitsch WK, Schollgen I, Terris DD. Matching physicians' treatment recommendations to patients' treatment preferences is associated with improvement in treatment satisfaction. J Eur Acad Dermatol Venereol 2013; 27:763-70.

27. Staiger TO, Jarvik JG, Deyo RA, Martin B, Braddock CH 3rd. BRIEF REPORT: Patient-physician agreement as a predictor of outcomes in patients with back pain. J Gen Intern Med 2005;20:935-7.
28. van der Heijde D, Kivitz A, Schiff MH, Sieper J, Dijkmans BA, Braun J, et al. Efficacy and safety of adalimumab in patients with ankylosing spondylitis: results of a multicenter, randomized, double-blind, placebo-controlled trial. Arthritis Rheum 2006;54:2136-46.

APPENDIX 1. Efficacy at Week 16 for patients with complete ankylosis at baseline. Data presented as n (\%) unless otherwise noted.

\begin{tabular}{lcc}
\hline Variables & Placebo & $\begin{array}{c}\text { Golimumab, } \\
2 \mathrm{mg} / \mathrm{kg}\end{array}$ \\
\hline Patients randomized, $\mathrm{n}$ & 7 & 5 \\
ASAS20 & 0 & $3(60.0)^{*}$ \\
ASAS40 & 0 & $1(20.0)$ \\
BASDAI50 & 0 & $1(20.0)$ \\
ASAS partial remission & 0 & 0 \\
ASDAS inactive disease & 0 & 0 \\
Change from baseline in BASFI, mean \pm SD & $0.7 \pm 0.7$ & $-1.1 \pm 2.0$ \\
Change from baseline in BASMI (linear), & & \\
mean \pm SD & $-0.02 \pm 0.55$ & $-0.34 \pm 0.36$ \\
\hline
\end{tabular}

$*$ p < 0.05. ASAS20/40: $\geq 20 \% / 40 \%$ improvement in ASsessment in Ankylosing Spondylitis (ASAS) International Working Group criteria; ASDAS: Ankylosing Spondylitis Disease Activity Score; BASDAI50: $\geq 50 \%$ improvement in Bath Ankylosing Spondylitis Disease Activity Index; BASFI: Bath Ankylosing Spondylitis Functional Index; BASMI: Bath Ankylosing Spondylitis Metrology Index. 


\section{Correction}

Safety and Efficacy of Golimumab Administered Intravenously in Adults with Ankylosing Spondylitis: Results through Week 28 of the GO-ALIVE Study

Deodhar A, Reveille JD, Harrison DD, Kim L, Lo KH, Leu JH, Hsia EC. Safety and efficacy of golimumab administered intravenously in adults with ankylosing spondylitis: results through week 28 of the GO-ALIVE study. J Rheumatol 2017; doi:10.3899/jrheum.170487. In Figure 2 of this article, the legend for Panel $\mathrm{C}$ is incorrect. The legend should read, "Placebo $\rightarrow$ Golimumab $2 \mathrm{mg} / \mathrm{kg}(\mathrm{n}=103)$ ".

This correction applies only to the December 15 First Release. The correct figure appears online and will appear in the March print edition.

doi:10.3899/jrheum.170487.C1 